\title{
Effects of Familial Characteristics on Dental Fear: A Cross-sectional Study
}

\author{
Osama M Felemban ${ }^{1}$, Mohammad A Alshoraim², Azza A El-Housseiny ${ }^{3}$, Najat M Farsi ${ }^{4}$
}

\begin{abstract}
Aim: Dental fear (DF) in children is a multifactorial problem that may affect the child's dental treatment and behavior at the dental office. This study aimed to evaluate the familial characteristics affecting DF among Arabic-speaking 12- to 15-year-old children in Jeddah, Saudi Arabia.

Materials and methods: A cross-sectional study assessing 16 middle schools in Jeddah, Saudi Arabia, was performed through multistage stratified random sampling. DF among children was measured using the children fear survey schedule-dental subscale (CFSS-DS) questionnaire. A parental questionnaire was used to collect information regarding familial socioeconomic status, parental DF, and DF among siblings and friends. The data were analyzed using the $t$ test, one-way analysis of variance (ANOVA), and multiple linear regression analysis.

Results: A total of 1,522 children were included. Socioeconomic variables were not associated with DF among children. Parental DF, parental dental experiences, siblings' DF, and friends' DF were significantly associated with DF in children. In the regression analysis, mothers' anxiety at the last dental visit, siblings' DF, and friends' DF were significant predictors of DF among children.

Conclusion: DF in children is associated with mothers' anxiety during their last dental visit and DF in siblings or friends.

Clinical significance: Obtaining comprehensive dental, family, and social history from patients is as essential as asking about medical history for pediatric dentists to plan the most appropriate and effective behavioral management techniques for their pediatric patients. Understanding the etiology of DF assists clinicians to provide better oral health services for their fearful patients.

Keywords: Cross-sectional studies, Dental anxieties, Dental fear, Dental phobia, Socioeconomic status.

The Journal of Contemporary Dental Practice (2019): 10.5005/jp-journals-10024-2567
\end{abstract}

\section{INTRODUCTION}

Fear is defined as a physical and emotional response to a consciously recognized threat or danger. ${ }^{1}$ Dental fear (DF) is a typical physiological, behavioral, and emotional reaction to one or more threatening stimuli in dental practice, such as injections or drilling. ${ }^{2}$ Anxiety is a personality trait characterized by apprehension, tension, or uneasiness that originates from the anticipation of danger, the source of which is mostly unknown or unrecognized. ${ }^{3}$ Dental anxiety (DA) is a patient's response to the stress specific to the dental situation. ${ }^{4}$ Dental fear and anxiety (DFA) is an umbrella term used to describe all kinds of fear and anxiety related to dentistry. ${ }^{5}$

DFA is a severe health problem that may persist into adolescence and, consequently, lead to avoidance of dental treatment and oral health deterioration. ${ }^{6}$ DFA has a multifactorial nature and can originate during childhood and persist through adolescence and adulthood. ${ }^{7}$ There is a significant relationship between DF and avoidance of dental treatment. Neglect of dental care may lead to dental decay and pain that necessitates visits to the dentist, which in turn increases the patient's original DF, thereby completing a vicious circle. ${ }^{8}$

Several factors are associated with DFA. These factors could be child- or family-related. Child-related factors that could affect DFA include demographic variables, previous dental experience, caries experience, and dental behavior. ${ }^{9}$ In contrast, the familyrelated factors include the socioeconomic status (SES) of the family, parental DFA, and siblings' and friends' DF. In general, children of low-SES families have more DF than children of high-SES families. ${ }^{10}$ In a study covering the four age groups of 5, 8, 12, and 15 years in the UK, Nuttall et al. determined low social class as a cofactor for DA. ${ }^{11}$ However, a recent study by Coric et al. found no association between SES and DFA in older children. ${ }^{12}$

\begin{abstract}
1,4Faculty of Dentistry, King Abdulaziz University, Jeddah, Kingdom of Saudi Arabia

${ }^{2}$ King Fahad General Hospital, Ministry of Health, Jeddah, Kingdom of Saudi Arabia

${ }^{3}$ Faculty of Dentistry, King Abdulaziz University, Jeddah, Kingdom of Saudi Arabia; Faculty of Dentistry, Alexandria University, Alexandria, Egypt

Corresponding Author: Osama M Felemban, Faculty of Dentistry, King Abdulaziz University, Jeddah, Kingdom of Saudi Arabia, Phone: +966 505529982, e-mail: omfelemban@kau.edu.sa

How to cite this article: Felemban OM, Alshoraim MA, et al. Effects of Familial Characteristics on Dental Fear: A Cross-sectional Study. J Contemp Dent Pract 2019;20(5):609-615.
\end{abstract}

Source of support: Nil

Conflict of interest: None

It is believed that part of a fear is learned, and one of the critical sources for learning during childhood is parents. ${ }^{13} \mathrm{~A}$ positive correlation between children's DF and parents' trait anxiety has been recognized..$^{14}$ In a recent study, Majstorovic et al. described parental DF as an indicator for DF in their children. ${ }^{15}$ Milsom et al. stated that parents with DF are twice as likely to have children with DFA than non-anxious parents. ${ }^{16}$ Mothers' negative attitudes and DFA toward dental treatment could be reflected in their children's oral health. ${ }^{17}$ However, Wu and Gao in a recent study from Hong Kong found no association between parental DA and DF in their children. ${ }^{18}$ DF can also be transmitted from other members of the family to the child. ${ }^{14}$ Classically, it was suggested that exposure to threatening information and cultural thoughts can lead to DF during childhood. ${ }^{7}$ Unfortunately, few studies have explored the

(c) The Author(s). 2019 Open Access This article is distributed under the terms of the Creative Commons Attribution 4.0 International License (https://creativecommons. org/licenses/by-nc/4.0/), which permits unrestricted use, distribution, and non-commercial reproduction in any medium, provided you give appropriate credit to the original author(s) and the source, provide a link to the Creative Commons license, and indicate if changes were made. The Creative Commons Public Domain Dedication waiver (http://creativecommons.org/publicdomain/zero/1.0/) applies to the data made available in this article, unless otherwise stated. 
association between DF in children and the DF in their siblings and friends. Paryab and Hosseinbor found no association between the anxiety of different family members and children DFA. ${ }^{19}$ Bedi et al. found that familiarity with an individual with DF was a significant predictor of DA in children. ${ }^{20}$ The purpose of this study was to evaluate the familial characteristics affecting DF among Arabicspeaking 12- to 15-year-old children in Jeddah, Saudi Arabia.

\section{Materials and Methods}

\section{Participants}

A cross-sectional study was conducted by distributing questionnaires to middle-school children in Jeddah, Saudi Arabia. The study was approved by the Research Ethics Committee, Faculty of Dentistry, King Abdulaziz University, Jeddah, Saudi Arabia (number:046-15). The reporting of the study followed the guidelines of the Strengthening the Reporting of Observational Studies in Epidemiology (STROBE) statement. ${ }^{21}$ For sample size calculation, it was assumed that the prevalence of DF was $20 \%$ with a $\pm 2 \%$ confidence limit. ${ }^{5}$ Thus, a sample size of 1,520 children was required to achieve an $85 \%$ power to detect statistically significant differences at a level of 0.05. To account for nonresponse and refusal to participate, 2,000 questionnaires were distributed. Middle-school children in Jeddah, Saudi Arabia, were sampled using a multistage-stratified random sampling method. The schools were stratified by geographical location into four districts. Within each district, schools were stratified into government and public schools. Since education is segregated in Saudi Arabia, schools were also stratified by gender within each district. The stratification process resulted in four strata within each of the four districts: female private schools, female government schools, male private schools, and male government schools. One school from each stratum was randomly selected. A total of 16 schools were included in the study. In large schools where the total number of students in the school was more than 150, a seventh-, an eighth-, and a ninth-grade class with more than 15 students in each class were randomly selected using the bowl method to be included in the study. If the class included less than 15 students, a second class of the same grade was randomly selected. If the selected school was small (the total number of students in the school was less than 150), all the students in the school were included. Consent forms written in Arabic and explaining the study were distributed to the students to be given to and signed by their parents.

\section{Questionnaire Assessments}

Two questionnaires were implemented in the study: a parent questionnaire and a child questionnaire. The parent questionnaire included 11 questions. The questionnaire asked about the parents' age and SES (occupation, education, income, and marital status). The parents' fear was assessed by asking them to rate their DF on a 5-point Likert scale (1, not afraid at all; 2 , slightly afraid; 3, quite afraid; 4, afraid; and 5, very afraid), which was later dichotomized into "yes" for score 1 or "no" for scores 2 to 5 . The parents were also asked if they had bad experiences at the dentist in their childhood. The parents' anxiety level was assessed using the short dental fear question (SDQF) ${ }^{22}$ which is a 4-point Likert scale question asking how their last dental visit went: 1 , I was totally relaxed during the treatment (relaxed); 2, I was nervous but, nevertheless, the treatment was carried out successfully (slightly frightened); 3, I was nervous; the treatment could only be just carried out (moderately frightened); and 4, I was so frightened and nervous that $(A)$ treatment was difficult (severely frightened), (B) the treatment did not succeed (severely frightened), or (C) I missed my appointment (severely frightened). The responses to the SDQF were dichotomized into relaxed (choice 1 ) and anxious (choices 2 , $3,4 A, 4 B$, and $4 C$ ). The parents were also asked about the number of siblings the participants had and the DF among their children's siblings and friends. The parents' questionnaire was developed by one of the authors based on the literature and reviewed by four different pediatric dentistry experts in behavior management.

The children's questionnaire consisted of demographic questions (age and gender) and the Arabic version of the children fear survey schedule-dental subscale (CFSS-DS). ${ }^{23}$ The CFSS-DS is a valid self-reported questionnaire that is commonly used to measure DF. ${ }^{24}$ The CFSS-DS consists of 15 items to quantify DF on a five-point Likert scale. The sum of the scores for the items ranges from 15, indicating low DF, to 75, which represents the highest score of DF. Previous studies showed that the Arabic version of CFSS-DS is highly reliable. It showed good internal consistency, good criterion validity, moderate construct validity, and high test-retest reliability. ${ }^{25,26}$

\section{Study Procedures}

The study was carried out over a 22-month period from September 2014 to June 2016. The examiners visited the included schools to distribute the consent form along with the parent questionnaires. The schools were then revisited to collect the signed consent forms and the parent questionnaires. Children with signed consent forms were asked to fill out the children's questionnaire. The children's questionnaires were inspected for completion before they were collected, and the children were asked to fill in any missing questions.

\section{Data Analysis}

The primary outcome of the study was the mean score of the CFSSDS. Associations between the mean CFSS-DS scores and parents' demographic characteristics, parental DF, parents' past dental experience, and siblings' and friends' reported DF were explored using independent $t$ tests or one-way analysis of variance (ANOVA). Significant results in ANOVA were further assessed using Tukey's post hoc analysis. All statistical analyses were performed using the Statistical Package for the Social Sciences (SPSS) software version 23.0 (IBM Corp, 2015) at a significance level of 0.05.

\section{Results}

Two thousand questionnaires were distributed, and 1,572 were returned by the children with signed consent forms (response rate $=$ 78.6\%). Thirty-one children were absent on the data collection day, and 19 children refused to fill in the children questionnaire. The final number of students included in the study was 1,522. The mean age of the children involved in the study was $13.50 \pm 1.05$ years, and more than half of the children were males (54.30\%). About twothirds of the included students were studying in private schools (67.50\%). The mean CFSS-DS score of the children was $25.99 \pm 9.31$ (95\% Cl 25.5-26.4). The mean age of the fathers was $47.16 \pm 7.95$ years and that of the mothers was $40.52 \pm 6.09$ years.

Table 1 explores the relationship between mean children DF scores and the SES of the parents. About $96 \%$ of the parents were married, and the rest were widowed or divorced. The relationship between the mean fear scores of the children and their parents marital status was neither significant for fathers $(p=0.676)$ nor for mothers ( $p=0.827$ ). The parents' education level was divided into three groups: less than secondary, secondary, and higher 
Table 1: Mean DF scores in children in relation to parents' SES

\begin{tabular}{|c|c|c|c|c|c|}
\hline Parents'SES & & $N(\%)$ & $D F$ mean $\pm S D$ & $95 \% \mathrm{Cl}$ & $p$ value \\
\hline \multirow[t]{3}{*}{ Mother marital status } & Married & $1,448(95.1 \%)$ & $25.95 \pm 9.3$ & $25.5-26.4$ & $0.827^{\ddagger}$ \\
\hline & Divorced & $50(3.3 \%)$ & $26.52 \pm 8.5$ & $24.1-28.9$ & \\
\hline & Widow & $24(1.6 \%)$ & $26.83 \pm 12.2$ & $21.7-32.0$ & \\
\hline \multirow[t]{3}{*}{ Father marital status ${ }^{\S}$} & Married & $1,462(94.3 \%)$ & $25.96 \pm 9.2$ & $25.5-26.4$ & $0.676^{\ddagger}$ \\
\hline & Divorced & $33(2.2 \%)$ & $26.88 \pm 10.3$ & $23.2-30.5$ & \\
\hline & Widow & $2(0.1 \%)$ & $21.50 \pm 6.3$ & $-35.7-78.7$ & \\
\hline \multirow[t]{3}{*}{ Mother education } & Less than secondary & $399(26.2 \%)$ & $26.48 \pm 9.11$ & $25.5-27.4$ & $0.262^{\ddagger}$ \\
\hline & Secondary school & 477 (31.4\%) & $25.80 \pm 9.02$ & $24.9-26.7$ & \\
\hline & Higher than secondary school & $646(42.4 \%)$ & $25.36 \pm 8.62$ & $24.7-26.1$ & \\
\hline \multirow[t]{3}{*}{ Father education ${ }^{\S}$} & Less than secondary & $238(15.6 \%)$ & $27.11 \pm 9.69$ & $25.8-28.4$ & $0.302^{\ddagger}$ \\
\hline & Secondary school & $404(26.5 \%)$ & $25.83 \pm 9.15$ & $24.9-26.8$ & \\
\hline & Higher than secondary school & $855(56.2 \%)$ & $25.39 \pm 8.38$ & $24.8-26.0$ & \\
\hline \multirow[t]{5}{*}{ Mother occupation } & Employee & $138(9.1)$ & $26.96 \pm 9.6$ & $25.3-28.6$ & $0.455^{\ddagger}$ \\
\hline & Professional & $229(15.0)$ & $25.20 \pm 8.6$ & $24.1-26.3$ & \\
\hline & Custodian & $15(1.0)$ & $24.40 \pm 6.1$ & $21.0-27.8$ & \\
\hline & Others & $27(1.8)$ & $25.74 \pm 10.3$ & $21.7-29.8$ & \\
\hline & Not working & $1,113(73.1)$ & $26.06 \pm 9.4$ & $25.5-26.6$ & \\
\hline \multirow[t]{6}{*}{ Father occupation ${ }^{\S}$} & Employee & $582(38.2)$ & $26.10 \pm 9.6$ & $25.3-26.9$ & $0.820^{\ddagger}$ \\
\hline & Professional & $306(20.1)$ & $25.97 \pm 9.1$ & $24.9-27.0$ & \\
\hline & Custodian & $64(2.4)$ & $24.31 \pm 6.6$ & $22.7-26.0$ & \\
\hline & Soldier & $229(15.0)$ & $25.98 \pm 9.6$ & $24.7-27.2$ & \\
\hline & Tradesman & $200(13.1)$ & $26.12 \pm 9.2$ & $24.8-27.4$ & \\
\hline & Not working & $116(7.6)$ & $25.97 \pm 8.7$ & $24.4-27.6$ & \\
\hline \multirow[t]{3}{*}{ Family income } & Adequate with saving & $297(19.5)$ & $24.95 \pm 9.1$ & $23.9-26.0$ & $0.102^{\ddagger}$ \\
\hline & Adequate & $1,080(71.0)$ & $26.24 \pm 9.4$ & $25.6-26.8$ & \\
\hline & Inadequate & $145(9.5)$ & $26.20 \pm 9.0$ & $24.7-27.7$ & \\
\hline
\end{tabular}

${ }^{\ddagger}$ Analysis of variance, ${ }^{\dagger} t$ test, ${ }^{\S}$ the total number is different since 25 (1.6\%) fathers were dead based on mothers' answers, and so the questions related to them were not answered

than secondary school. On the one hand, among the fathers, 238 (15.6\%) had less than secondary school education, 404 (26.5\%) had secondary school education, and 855 (56.2) had higher than secondary school education. On the other hand, 399 (26.2\%) of the mothers had less than secondary school education, 477 (31.4\%) had secondary school education, and 646 (42.4) had higher than secondary school education. However, no significant differences were found between mean DF scores among children of parents with different education levels for fathers $(p=0.302)$ and for mothers ( $p=0.262$ ). Among the fathers, $582(38.2 \%)$ were employees, 306 (20.1\%) worked in professional jobs, 64 (2.4\%) were custodians, 229 (15\%) were soldiers, 200 (13.1\%) were tradesmen, and 116 (7.6\%) were unemployed. Table 1 indicates that the differences in the mean DF scores of children in relation to their parents' occupation were not significant for fathers $(p=0.820)$ or mothers $(p=0.455)$. The family income was also assessed, and 297 (19.5\%) of the parents reported having adequate income with savings, 1,080 (71\%) had adequate income, and 145 (9.5\%) had inadequate income. The mean fear scores among different family income levels were also not significantly different $(p=0.102)$.

Table 2 explores the relationship between the parents' DF and their children's DF. Children of fearful fathers had a mean fear score of $27.63 \pm 10.54$, which was significantly higher than the mean score of children with non-fearful fathers $(25.60 \pm 8.92 ; p=0.001)$. Children of fearful mothers also had significantly higher mean fear scores than children of non-fearful mothers $(p<0.0001)$. Furthermore, the mean fear scores of children in relation to their fathers' bad dental experiences were significantly higher than those in the other groups $(p=0.020)$. However, there was no significant difference between these children in the post hoc analysis. On the contrary, the mean fear scores of children in relation to their mothers' dental experience were significantly different from those of the other groups ( $p=$ 0.012 ), and post hoc analysis indicated that children of mothers with previous bad dental experience were significantly more fearful than children of mothers without previous bad dental experiences. Moreover, children of fathers who were anxious in their last dental visit had a significantly higher mean fear score compared to children of fathers who were relaxed in their last dental visit ( $p=0.013)$. The same relationship was found between the mothers' anxiety levels at their last dental visit and the children's fear score $(p<0.0001)$.

Table 3 indicates that DF in children was not associated with the number of brothers or sisters. Children's DF in relation to DF in siblings and friends was assessed. Children with fearful siblings or friends had significantly higher mean fear scores than the other children ( $p<0.0001$ for both siblings and friends). Children with highly fearful siblings had the highest mean fear score $(29.86 \pm$ 12.11). Post hoc analysis indicated that children with "very afraid siblings" had significantly higher mean fear scores than children with "no siblings," "non-fearful siblings," and "slightly afraid sibling." In addition, children with "no siblings" and "not afraid at all" siblings had the lowest mean fear scores, and these scores were significantly lower than the mean fear scores of all other children. 
Table 2: Mean children fear scores in relation to parents' DF and parents' dental experiences

\begin{tabular}{|c|c|c|c|c|c|}
\hline Parents' past dental history & & $N(\%)$ & Mean $\pm S D$ & $95 \% \mathrm{Cl}$ & $p$ value \\
\hline \multirow[t]{2}{*}{ Father had DF ${ }^{\S}$} & Yes & $274(18)$ & $27.63 \pm 10.54$ & $26.4-28.9$ & $0.001^{\dagger *}$ \\
\hline & No & $1,223(80.3)$ & $25.60 \pm 8.92$ & $25.1-26.1$ & \\
\hline \multirow[t]{2}{*}{ Mother had DF } & Yes & $657(43.2)$ & $27.13 \pm 9.8$ & $26.4-27.9$ & $<0.0001^{\dagger *}$ \\
\hline & No & $865(56.8)$ & $25.12 \pm 8.8$ & $24.5-25.7$ & \\
\hline \multirow{3}{*}{$\begin{array}{l}\text { Father had a bad experience } \\
\text { at the dentist as a child }\end{array}$} & Yes & $182(12)$ & $26.99 \pm 10.3$ & $25.5-28.4$ & $0.02^{\ddagger *}$ \\
\hline & No & $953(62.6)$ & $25.45 \pm 8.9$ & $24.9-26.0$ & \\
\hline & Do not remember & $362(23.8)$ & $26.74 \pm 9.5$ & $25.8-27.7$ & \\
\hline \multirow{3}{*}{$\begin{array}{l}\text { Mother had a bad experience } \\
\text { at the dentist as a child }\end{array}$} & Yes & $272(17.9)$ & $27.44 \pm 10.2^{\mathrm{a}}$ & $26.2-28.7$ & $0.012^{\ddagger *}$ \\
\hline & No & $874(57.4)$ & $25.52 \pm 9.1^{b}$ & $24.9-26.1$ & \\
\hline & Do not remember & $376(24.7)$ & $26.04 \pm 9.1^{\mathrm{ab}}$ & $25.1-27.0$ & \\
\hline \multirow[t]{2}{*}{ Father's last dental visit ${ }^{\S}$} & Relaxed & $1,019(67)$ & $25.56 \pm 9.0$ & $25.0-26.1$ & $0.013^{\dagger *}$ \\
\hline & Anxious & $478(31.4)$ & $26.84 \pm 9.7$ & $26.0-27.7$ & \\
\hline \multirow[t]{2}{*}{ Mother's last dental visit } & Relaxed & $699(45)$ & $24.72 \pm 8.6$ & $24.1-25.3$ & $<0.0001^{\dagger *}$ \\
\hline & Anxious & $823(54)$ & $27.08 \pm 9.8$ & $26.4-27.7$ & \\
\hline
\end{tabular}

${ }^{*}$ Statistically significant $(p<0.05),{ }^{*}$ analysis of variance, ${ }^{\dagger} t$ test

Means sharing the same superscript alphabetical letter are not significantly different from each other (post hoc, $p \geq 0.05$ )

Means that have different superscript alphabetical letters are significantly different from each other (post hoc, $p<0.05$ )

${ }^{\S}$ The total number is different since $25(1.6 \%)$ fathers were dead based on the mothers' answers, and so the questions related to them were not answered

Table 3: Mean children DF scores in relation to siblings' and friends' DF

\begin{tabular}{|c|c|c|c|c|c|}
\hline Siblings factors & & $N(\%)$ & $D F$ mean $\pm S D$ & $95 \% \mathrm{Cl}$ & $p$ value \\
\hline \multirow[t]{4}{*}{ Number of brothers } & 0 & $102(6.7 \%)$ & $25.39 \pm 7.80$ & $23.8-27.0$ & 0.235 \\
\hline & 1 & $343(22.5 \%)$ & $25.69 \pm 9.13$ & $24.7-26.7$ & \\
\hline & 2 & $464(30.5 \%)$ & $25.57 \pm 9.68$ & $25.6-27.4$ & \\
\hline & 3 or more & $613(40.3 \%)$ & $25.35 \pm 8.23$ & $24.7-26.0$ & \\
\hline \multirow[t]{4}{*}{ Number of sisters } & 0 & 159 (10.5\%) & $24.06 \pm 8.09$ & $22.7-25.4$ & 0.068 \\
\hline & 1 & $377(24.8 \%)$ & $25.98 \pm 8.88$ & $25.0-26.9$ & \\
\hline & 2 & 395 (26.0\%) & $25.59 \pm 8.43$ & $24.7-26.5$ & \\
\hline & 3 or more & $589(38.7 \%)$ & $26.25 \pm 9.32$ & $25.4-27.0$ & \\
\hline \multirow{7}{*}{$\begin{array}{l}\text { The degree of DF in any of the } \\
\text { child's sibling(s)? }\end{array}$} & Not afraid at all & $427(28.1)$ & $23.55 \pm 7.6^{\mathrm{a}}$ & $22.8-24.3$ & $<0.0001^{\ddagger *}$ \\
\hline & A little afraid & $541(35.5)$ & $26.38 \pm 9.1^{b}$ & $25.6-27.1$ & \\
\hline & A fair amount afraid & $148(9.7)$ & $27.51 \pm 8.6^{b c}$ & $26.1-28.9$ & \\
\hline & Pretty much afraid & $145(9.5)$ & $27.80 \pm 10.6^{\mathrm{bd}}$ & $26.0-29.5$ & \\
\hline & Very afraid & $87(5.7)$ & $29.86 \pm 12.1^{\text {cde }}$ & $27.2-32.4$ & \\
\hline & No sibling & $25(1.6)$ & $21.36 \pm 4.4^{\mathrm{a}}$ & $19.5-23.1$ & \\
\hline & I do not know & $149(9.8)$ & $26.79 \pm 10.4^{\text {be }}$ & $25.0-28.5$ & \\
\hline \multirow[t]{3}{*}{ Do any of child friend(s) have DF? } & Yes & $370(24.3)$ & $28.33 \pm 10.4^{\mathrm{a}}$ & $27.2-29.4$ & $<0.0001^{\ddagger * *}$ \\
\hline & No & $378(24.8)$ & $24.37 \pm 7.6^{\mathrm{b}}$ & $23.6-25.1$ & \\
\hline & I don't know & $774(50.9)$ & $25.65 \pm 9.3^{b}$ & $25.0-26.3$ & \\
\hline
\end{tabular}

${ }^{*}$ Statistically significant $(p<0.05),{ }^{\ddagger}$ analysis of variance, ${ }^{\dagger} t$ test

Means sharing the same superscript alphabetical letters are not significantly different from each other (post hoc, $p \geq 0.05$ )

Means that have different superscript alphabetical letters are significantly different from each other (post hoc, $p<0.05$ )

Post hoc analysis also indicated that children with fearful friends had significantly higher mean fear scores than children with nonfearful friends or children whose parents did not know if their friends had DF or not.

To control for confounding among the associations between children's DF and the multiple significant variables in the bivariate analysis, a multiple linear regression model was developed (Table 4). Parental DF and bad experiences at the dentist when they were children were not significant predictors of DF in children after controlling for confounding. However, children of mothers who were anxious at their last dental visit had a significantly higher CFSS-DS score than the children of mothers who were relaxed during their last dental visit. In contrast, fathers' anxiety at their last dental visit did not significantly affect their children's DF. Interestingly, as the degree of fear in the child siblings increased, the child's DF significantly increased in comparison to the DF in 
Table 4: Crude and adjusted multiple linear regression model

\begin{tabular}{|c|c|c|c|c|c|c|}
\hline \multirow[t]{2}{*}{ Variable name } & \multicolumn{3}{|l|}{ Crude } & \multicolumn{3}{|l|}{ Adjusted } \\
\hline & $\beta(S E)$ & $95 \% \mathrm{Cl}$ & pvalue & $\beta(S E)$ & $95 \% \mathrm{Cl}$ & $p$ value \\
\hline \multicolumn{7}{|l|}{ Mother had DF } \\
\hline Yes & $1.68(0.49)$ & $0.73-2.63$ & $0.001^{*}$ & $0.247(0.53)$ & $-0.85-1.37$ & 0.665 \\
\hline No & Ref & - & & Ref & - & - \\
\hline \multicolumn{7}{|l|}{ Father had DF } \\
\hline Yes & $1.11(0.63)$ & $0.12-2.34$ & 0.076 & $0.05(0.71)$ & $-1.35-1.44$ & 0.946 \\
\hline Yes & $1.65(0.65)$ & $0.37-2.93$ & $0.012^{*}$ & $0.16(0.72)$ & $-1.25-1.58$ & 0.822 \\
\hline Do not remember & $0.78(0.57)$ & $-0.35-1.90$ & 0.174 & $-0.45(0.71)$ & $-1.83-0.93$ & 0.523 \\
\hline No & Ref & - & - & Ref & - & - \\
\hline \multicolumn{7}{|c|}{$\begin{array}{l}\text { Father had a bad experience at the dentist } \\
\text { as a child }\end{array}$} \\
\hline No & Ref & - & - & Ref & - & - \\
\hline \multicolumn{7}{|c|}{ Mother's last dental visit } \\
\hline Anxious & $2.14(0.48)$ & $1.20-3.09$ & $<0.001^{*}$ & $1.79(0.56)$ & $0.70-2.88$ & $0.001^{*}$ \\
\hline Relaxed & Ref & - & & Ref & - & - \\
\hline \multicolumn{7}{|c|}{ Father's last dental visit } \\
\hline Anxious & $0.81(0.52)$ & $-0.20-1.83$ & 0.117 & $-0.83(0.59)$ & $-1.99-0.33$ & 0.160 \\
\hline Relaxed & Ref & - & - & Ref & - & - \\
\hline \multicolumn{7}{|c|}{ The degree of DF for any of child's sibling(s)? } \\
\hline Slightly afraid & $2.48(0.60)$ & $1.30-3.65$ & $<0.001^{*}$ & $2.02(0.61)$ & $0.82-3.22$ & $0.001^{*}$ \\
\hline Quite afraid & $3.87(0.88)$ & $2.14-5.59$ & $<0.001^{*}$ & $2.66(0.90)$ & $0.90-4.42$ & $0.003^{*}$ \\
\hline I do not know & $1.10(0.59)$ & $-0.06-2.26$ & 0.062 & $0.36(0.60)$ & $-0.82-1.55$ & 0.551 \\
\hline No & Ref & - & - & Ref & - & - \\
\hline
\end{tabular}

*Statistically significant $(p<0.05)$

children whose siblings were not afraid at all of the dental visit. Children who had no siblings showed lower DF scores than those in children with siblings who did not have DF, but this difference was not statistically significant. Having friends with DF significantly increased the child's DF (by 2.93) in comparison with the DF in children with friends who did not have any DF.

\section{Discussion}

This cross-sectional study aimed to assess the relationship between familial characteristics (SES, parental DF, parental dental experience, and siblings' and friends' DF) and DF in children in Jeddah, Saudi Arabia. Several characteristics were found to be associated with children DF. However, the results of the regression analysis showed that the familial characteristics that influenced children's DF after adjusting for confounding were as follows: mothers' anxiety during the last dental visit, siblings with DF, and friends with DF.
The findings of the present study showed no significant differences in fear levels in children in relation to their parents' education, occupation, and marital status. These findings are in accordance with the study of Coric et al. among children aged 7 to 15 years, which found no significant differences in DFA in children in relation to socioeconomic variables, such as parents' education, employment, family income, marital status, or the number of children in a family. ${ }^{12}$ It has been suggested that the differences in DF between underdeveloped and developed populations could be explained by the low SES of underdeveloped countries, which results in more stress and thereby more DF. ${ }^{27}$ Even in a population with a high prevalence of DA, children from higher socioeconomic classes have significantly lower DA than those from the low to middle socioeconomic classes. ${ }^{28}$ Ingman et al. studied Nigerian and Kenyan children and found that DF was much higher than that in western European studies. The author attributed these differences to the low SES of African countries and different social situations. ${ }^{27}$ 
In addition, Ten Berge et al. in the Netherlands determined that two main factors significantly affecting the DF score in the Netherlands were child gender and child cultural background. Non-Western children showed higher CFSS-DS scores compared to Western children in the same population. ${ }^{29}$ The effect of SES on different life aspects, such as behavioral, social, economic, and psychological status, may explain the high DF in low-SES populations. ${ }^{30}$

However, the effect of parents' education on children's DF seems to be controversial. While studies have shown that children of parents with high educational levels are more fearful, ${ }^{31,32}$ Milgrom et al. in the United States found the opposite ${ }^{33}$ and Colares et al. in Brazil reported that mothers' schooling leads to lower DA in their children. ${ }^{34}$ El-Housseiny et al. suggested that the variations in the effect of parental education on DF are due to the social and cultural variations between populations. ${ }^{32}$ In the current study, there were no differences in the DF mean scores in relation to the family income. Recently, Assuncao et al. used two types of scales-dental anxiety scale (DAS) and trait anxiety scale (TAS) — for children, adolescents, and their parents to assess the association between DFA and family income. They found significantly higher scores for both types of anxiety in low-income families than in medium-income families among children, adolescents, and parents. They also observed a difference between medium- and high-income families, but it was nonsignificant. $^{14}$

A review by Klingberg and Broberg ${ }^{5}$ noted a significant relationship between parents' DFA and children's DFA in most studies. In addition, a significant relationship between parents' and children's DFA has been established in many longitudinal and crosssectional studies, ${ }^{15,16,34-36}$ although a recent study contradicted these results. ${ }^{18}$ It seems that maternal DA has a substantial effect on the children. A significant positive correlation between mothers' DA and their children's DA has been reported. ${ }^{37}$ The present results confirmed these findings and showed that the children of anxious mothers were significantly more fearful than the children of mothers with no DF. Since mothers develop an early psychological attachment with their children, the effect of their DFA is expected to be greater than the impact of the fathers' DF status. ${ }^{15}$ In addition to the parents' fear levels, their history of dental experiences can also affect DF in children. The current results indicated that children of parents with bad dental experiences are more fearful than other children. It has been confirmed previously that parents remember their horrible childhood experiences in dental treatment and repeat it with their children. ${ }^{38}$

In assessments of the effect of siblings' and friends' DF on the child's DF, children with "very afraid" siblings were significantly more fearful than children with "no siblings" or with "not afraid siblings." In addition, children who had fearful friends were significantly more fearful than those with non-fearful friends. At this stage of emotional development (12-17 years), the peer group is an important role model to the adolescent, which may explain the significant relationship with friends' DF found in the present study. ${ }^{39}$ This was supported by Suprabha et al. ${ }^{40}$ who showed that the presence of a fearful sibling in the family is associated with DF. Locker et al. discussed the origin of DA and reported that DA in family members, either parents or siblings, is a predictor of DA development in childhood. ${ }^{7}$ These findings support the Rachman theory regarding the acquisition of fear. While DF originates mainly from direct personal experience, the reception of frightening information plays a role in the acquisition of DF even if its role is minor. ${ }^{13}$ In contrast to these data, Paryab and Hosseinbor did not find a relationship between family members' DA and children's DA.
Their study reported that the effect of familial factors on DA is minor since DA is a situational anxiety more than a trait anxiety. However, they also mentioned that they used a different methodology, wherein children completed the questionnaire in the dental clinic under the supervision of a dental assistant and not at home with their parents. ${ }^{19}$

Information was gathered from a moderately large, randomly selected sample with different foundations. Published and approved psychometric scales were utilized to quantify child-rearing styles and the DF of the children and their siblings. Since parents may tend to give socially acceptable answers and their observations may not genuinely mirror the truth, registering the children's own reactions was ideal. Dependable answers could be acquired from young people through legitimate wording of the inquiries.

There are some limitations in this study. This investigation is cross-sectional in nature. Hence, no transient relationship can be set up, and our discoveries could just propose affiliations but not causation. The results of this survey were obtained from children in Saudi Arabia and cannot be straightforwardly extrapolated to different populations, although some valuable ramifications can be drawn, particularly for populations of comparative societies and social settings.

\section{Conclusions}

In conclusion, assessment of the relationship between familial characteristics (SES, parental DF, parental dental experience, and DF in siblings and friends) and DF in children revealed that the familial characteristics that influenced DF in children were mothers' anxiety during the last dental visit and DF in siblings and friends.

\section{Clinical Significance}

DF is not uncommon among children and might have an impact on their overall quality of life. Obtaining comprehensive dental, family, and social history from patients during the dental visit is as essential as taking medical history for pediatric dentists to plan the most appropriate and effective behavioral management techniques for their pediatric patients. Understanding the etiology of DF assists clinicians to provide better oral health services for their fearful patients.

\section{ACKNOWLedgments}

The authors would like to thank the schools and teachers who assisted in conducting the study and all the children and parents who spent their time to participate in the study. The authors would also like to thank Editage (www.editage.com) for language editing of the manuscript.

\section{References}

1. Gordon SM, Dionne RA, et al. Dental fear and anxiety as a barrier to accessing oral health care among patients with special health care needs. Spec Care Dentist 1988;18(2):88-92.

2. Nigam AG, Marwah N, et al. Correlation of general anxiety and dental anxiety in children aged 3 to 5 years: a clinical survey. J Int Oral Health 2013;5(6):18-24.

3. Johnsen DC. Managing the patient and parents in dental practice. In: Pediatric Dentistry: Total Patient Care. Wei SHY. ed. Philadelphia: Lea \& Febiger, 1988, vol. 1, pp. 140-155.

4. Corah NL, Gale EN, et al. Assessment of a dental anxiety scale. J Am Dent Assoc 1978;97(5):816-819. 
5. Klingberg G, Broberg AG. Dental fear/anxiety and dental behaviour management problems in children and adolescents: a review of prevalence and concomitant psychological factors. Int J Paediatr Dent 2007;17(6):391-406. DOI: 10.1111/j.1365-263X.2007.00872.x.

6. Oba AA, Dulgergil CT, et al. Prevalence of dental anxiety in 7 to 11 year-old children and its relationship to dental caries. Med Princ Pract 2009;18(6):453-457. DOI: 10.1159/000235894.

7. Locker D, Liddell A, et al. Age of onset of dental anxiety. J Dent Res 1999;78(3):790-796. DOI: 10.1177/00220345990780031201.

8. Moore R, Brodsgaard I, et al. The contribution of embarrassment to phobic dental anxiety: a qualitative research study. BMC Psychiatry 2004;4:10. DOI: 10.1186/1471-244X-4-10.

9. Alshoraim MA, El-Housseiny AA, et al. Effects of child characteristics and dental history on dental fear: cross-sectional study. BMC Oral Health 2018;18(1):33. DOI: 10.1186/s12903-018-0496-4.

10. Silveira ERd, Goettems ML, et al. Clinical and individual variables in children's dental fear: a school-based investigation. Braz Dent J 2017;28(3):398-404. DOI: 10.1590/0103-6440201601265.

11. Nuttall NM, Steele JG, et al. The reported impact of oral condition on children in the United Kingdom, 2003. Br Dent J 2006;200(10):551-556. DOI: 10.1038/sj.bdj.4813586.

12. Coric A, Banozic A, et al. Dental fear and anxiety in older children: an association with parental dental anxiety and effective pain coping strategies. J Pain Res 2014;7:515. DOI: 10.2147/JPR.S67692.

13. Rachman S. The conditioning theory of fear acquisition: a critical examination. Behav Res Ther 1977;15(5):375-387.

14. Assuncao CM, Losso EM, et al. The relationship between dental anxiety in children, adolescents and their parents at dental environment. J Indian Soc Pedod Prev Dent 2013;31(3):175-179. DOI: 10.4103/0970-4388.117977.

15. Majstorovic $M$, Morse $D E$, et al. Indicators of dental anxiety in children just prior to treatment. J Clin Pediatr Dent 2014;39(1):12-17.

16. Milsom KM, Tickle $M$, et al. The relationship between anxiety and dental treatment experience in 5 year-old children. Br Dent $\mathrm{J}$ 2003;194(9):503-506. DOI: 10.1038/sj.bdj.4810070.

17. Goettems ML, Ardenghi TM, et al. Children's use of dental services: influence of maternal dental anxiety, attendance pattern, and perception of children's quality of life. Community Dent Oral Epidemiol 2012;40(5):451-458. DOI: 10.1111/j.1600-0528.2012.00694.x.

18. Wu L, Gao X. Children's dental fear and anxiety: exploring family related factors. BMC Oral Health 2018;18(1):100. DOI: 10.1186/s12903018-0553-z.

19. Paryab M, Hosseinbor M. Dental anxiety and behavioral problems: a study of prevalence and related factors among a group of Iranian children aged 6 to 12. J Indian Soc Pedod Prev Dent 2013;31(2):82. DOI: 10.4103/0970-4388.115699.

20. Bedi $R$, Sutcliffe $P$, et al. The prevalence of dental anxiety in a group of 13 and 14 year old Scottish children. Int J Paediatr Dent 1992;2(1): 17-24.

21. Vandenbroucke JP, von Elm E, et al. Strengthening the reporting of observational studies in epidemiology (STROBE): explanation and elaboration. Epidemiology 2007;18(6):805-835. DOI: 10.1097/ EDE.0b013e3181577511.
22. Jaakkola $S$, Rautava $P$, et al. Dental fear: one single clinical question for measurement. Open Dent J 2009;3:161-166. DOI: $10.2174 / 1874210600903010161$.

23. El-Housseiny AA, Alamoudi NM, et al. Characteristics of dental fear among Arabic-speaking children: a descriptive study. BMC Oral Health 2014;14(1):118. DOI: 10.1186/1472-6831-14-118.

24. Al-Namankany $A$, De Souza $M$, et al. Evidence-based dentistry: analysis of dental anxiety scales for children. Br Dent J 2012;212(5):219-222. DOI: 10.1038/sj.bdj.2012.174.

25. El-Housseiny AA, Alsadat FA, et al. Reliability and validity of the children's fear survey schedule-dental subscale for Arabic-speaking children: a cross-sectional study. BMC Oral Health 2016;16:49. DOI: 10.1186/s12903-016-0205-0.

26. El-Housseiny AA, Farsi NM, et al. Assessment for the children's fear survey schedule-dental subscale. J Clin Pediatr Dent 2014;39(1):40-46.

27. Ingman KA, Ollendick TH, et al. Cross-cultural aspects of fears in African children and adolescents. Behav Res Ther 1999;37(4):337-345.

28. Taani DQ. Dental attendance and anxiety among public and private school children in Jordan. Int Dent J 2002;52(1):25-29.

29. Ten Berge M, Veerkamp JSJ, et al. The etiology of childhood dental fear: the role of dental and conditioning experiences. J Anxiety Disord 2002;16(3):321-329.

30. Armfield JM, Spencer AJ, et al. Dental fear in Australia: who's afraid of the dentist? Aust Dent J 2006;51(1):78-85.

31. Rantavuori K, Lahti S, et al. Dental fear and oral health and family characteristics of Finnish children. Acta Odontol Scand 2004;62(4):207-213. DOI: 10.1080/00016350410001586.

32. El-Housseiny AA, Merdad LA, et al. Effect of child and parent characteristics on child dental fear ratings: analysis of short and full versions of the children fear survey schedule-dental subscale. OHDM 2015;14(1):9-16.

33. Milgrom $P$, Mancl $L$, et al. Origins of childhood dental fear. Behav Res Ther 1995;33(3):313-319.

34. Colares V, Franca C, et al. Dental anxiety and dental pain in 5 to 12 yearold children in Recife, Brazil. Eur Arch Paediatr Dent 2013;14(1):15-19. DOI: 10.1007/s40368-012-0001-8.

35. Klaassen MA, Veerkamp JSJ, et al. Changes in children's dental fear: a longitudinal study. Eur Arch Paediatr Dent 2008;9(1):29-35.

36. Tickle $\mathrm{M}$, Jones $\mathrm{C}$, et al. A prospective study of dental anxiety in a cohort of children followed from 5 to 9 years of age. Int J Paediatr Dent 2009;19(4):225-232. DOI: 10.1111/j.1365-263X.2009.00976.x.

37. Alaki S, Alotaibi A, et al. Dental anxiety in middle school children and their caregivers: prevalence and severity. J Dent Oral Hygiene 2012;4(1):6-11.

38. Smith PA, Freeman R. Remembering and repeating childhood dental treatment experiences: parents, their children, and barriers to dental care. Int J Paediatr Dent 2010;20(1):50-58. DOI: 10.1111/j.1365263X.2009.01004.X.

39. Proffit WR, Fields HW, et al. Contemporary orthodontics, 5th edn. St. Louis, MO: Mosby Elsevier; 2014.

40. Suprabha BS, Rao A, et al. Child dental fear and behavior: the role of environmental factors in a hospital cohort. J Indian Soc Pedod Prev Dent 2011;29(2):95. DOI: 10.4103/0970-4388.84679. 